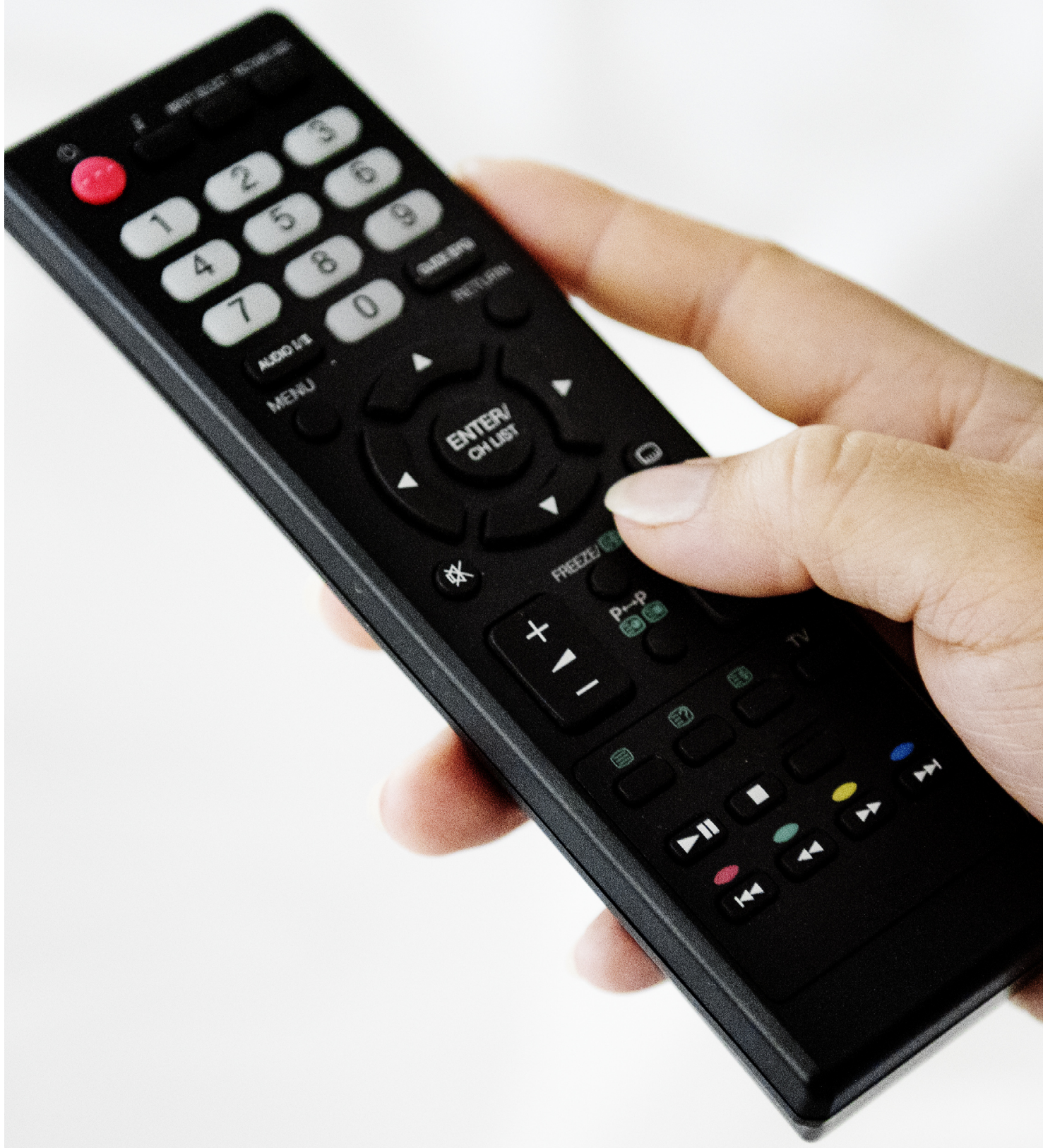

DOI: $10.5380 / 2238-0701.2021 \mathrm{n} 22.09$

Data de Recebimento: 20/04/2020

Data de Aprovação: 27/01/2021 
A Indústria Televisiva Sul-Coreana no Contexto Global 


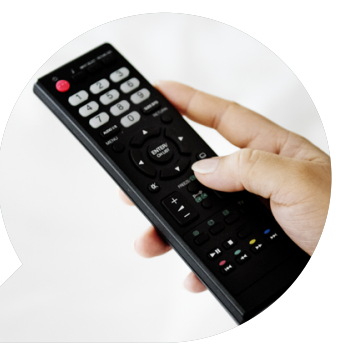

\title{
A Indústria Televisiva Sul-Coreana no Contexto Global
}

\author{
The South Korean Television Industry in the \\ Global Context
}

La Industria Televisiva de Corea del Sur en el Contexto Global

DANIELA MAZUR ${ }^{1}$

Resumo: Em meio aos fluxos globalizantes, novos polos de produção televisiva conquistam o interesse de telespectadores internacionais. Um desses casos é a Coreia do Sul, que hoje exporta dramas de TV e reality shows para diversos países do mundo, conquistando audiências em países distantes tanto geograficamente quanto culturalmente. Então, partindo de uma perspectiva desocidentalizante, esse artigo propõe-se a um levantamento introdutório sobre a forma de produzir e pensar a televisão no contexto sul-coreano, considerando questões intrínsecas a essa indústria e seus fluxos de circulação regionais e globais.

Palavras-chave: Televisão sul-coreana; Hallyu; Fluxos globais televisivos.

1 Doutoranda (2018-2022) pelo Programa de Pós-graduação em Comunicação da UFF e pesquisadora vinculada ao MidiÁsia e ao TeleVisões. 


\begin{abstract}
In the midst of globalizing flows, new centers of television production conquer the attention of international viewers. One of these cases is South Korea, which today exports TV dramas and reality shows to various countries around the world, conquering audiences in distant countries both geographically and culturally. Therefore, from a de-Westernizing perspective, this article proposes an introductory survey on how television is produced and thought in the South Korean context, considering issues intrinsic to this industry and its regional and global circulation flows.
\end{abstract}

Keywords: South Korean television; Hallyu; Global television flows.

Resumen: En medio de los flujos de globalización, los nuevos centros de producción de televisión están ganando el interés de los televidentes internacionales. Uno de estos casos es Corea del Sur, que hoy exporta dramas de televisión y reality shows a varios países del mundo, ganando audiencias en países distantes, tanto geográfica como culturalmente. Entonces, desde una perspectiva des-occidental, este artículo propone una encuesta introductoria sobre cómo producir y pensar la televisión en el contexto surcoreano, considerando temas intrínsecos a esta industria y sus flujos de circulación regionales y globales.

Palabras clave: Televisión surcoreana; Hallyu; Transmisiones mundiales de televisión.

\title{
Introdução
}

Graças aos inúmeros avanços tecnológicos no atual contexto global, os fluxos televisivos se encontram mais desterritorializados, possibilitando o consumo e acesso a produtos oriundos de várias localidades do mundo. Desde as tradicionais séries estadunidenses e britânicas até as novelas angolanas, passando pelos animes japoneses e novelas mexicanas, todos estão, em teoria, ao alcance de um clique ou presentes nas grades de canais abertos e fechados de diferentes países. O próprio Brasil é referência de produção e exportação de telenovelas pelo mundo desde os anos 1970. Existe, então, um crescente 
interesse e consumo de produtos televisivos que não fazem parte apenas do eixo central, formado especialmente pelos Estados Unidos e Reino Unido, mas também de polos de produção de países da dita periferia global. Um exemplo categórico dessa movimentação dentro do âmbito dos fluxos televisivos globais é a ascensão da Turquia, que se tornou a segunda maior exportadora de ficção seriada televisiva do mundo, atrás apenas dos Estados Unidos ${ }^{2}$. Os dramas turcos conquistaram o mundo árabe e outros países da Europa e das Américas (BERG, 2017), desafiando a hegemonia estadunidense nos fluxos globais. Assim como a Turquia se posiciona como uma peça importante nos fluxos globais da televisão, também está a Coreia do Sul com seu intenso mercado de dramas televisivos no Leste e Sudeste Asiático.

Tais movimentações globais de conteúdos televisivos são exemplos de um levante periférico e não-ocidental que aponta para a descentralização dos fluxos de influências globais, antes estritamente polarizados ao eixo central, para um ambiente mais multipolar. Assistimos, hoje, novos polos de criação de conteúdo midiático ganhando credibilidade e se difundindo pelo mundo. O processo tradicional de globalização nos apresenta o Ocidente como peça central do cenário global, estabelecendo as áreas restantes como periféricas a partir do centro (HALL, 1992; ALBUQUERQUE; CORTEZ, 2015). Contudo, essa lógica tem sido desafiada pelos países de "fora do eixo", como a Coreia do Sul. Com o levante da internet como ferramenta fundamental de difusão de conteúdo, diferentes modos de produzir televisão começaram a ser disseminados por plataformas online e estão conquistando fãs pelo mundo. A Coreia do Sul se destaca pelo desenvolvimento acelerado de sua indústria televisiva nas últimas décadas e se apresenta como uma das maiores produtoras e exportadoras de conteúdos televisivos da Ásia na atualidade, se consolidando como uma estável influência cultural na sua região (RYOO, 2009; JOO, 2011) e em progressiva expansão para outras regiões do mundo.

A Coreia do Sul atualmente é reconhecida no cenário internacional por questões que transcendem o militarismo e seu histórico conturbado com países vizinhos, mas essa atualização de seu imaginário nacional é recente. A indústria da cultura pop sul-coreana construiu e apresenta uma nova faceta do país através do seu fenômeno cultural de caráter

2 "Turkish second largest TV series exporter" - Daily Sabah News, publicado em 18/10/2016: https://www. dailysabah.com/business/2016/10/19/turkey-second-largest-tv-series-exporter 
transnacional conhecido como "Onda Coreana", ou Hallyu. Esse levante abarca o intenso e crescente fluxo de produtos culturais provenientes da Coreia do Sul, que tem alcançado grande popularidade na Ásia e, mais recentemente, no Ocidente (SHIM, 2006; HANAKI et al., 2007; HUANG, 2011; CHAN; WANG, 2011). Tal fluxo abarca filmes, música, programação televisiva, videogames, gastronomia e outros artefatos culturais, porém suas duas principais vertentes de expansão são o K-pop (música pop sul-coreana) e os K-dramas (dramas de TV sul-coreanos). O K-pop é reconhecido por ter potencializado o alcance da cultura pop sul-coreana para além da Ásia, conquistando admiradores em países geográfica e culturalmente distantes, contudo o papel dos K-dramas tem um peso ainda maior nessa equação: foram os precursores da Hallyu como um fenômeno transnacional de exportação (SHIM, D., 2008).

Através do sucesso dos K-dramas especialmente em países vizinhos, outros produtos da TV sul-coreana começaram a ser exportados, como os reality shows e os programas de variedade, tanto como produtos licenciados (legendados e/ou dublados para serem exibidos a públicos de outras nacionalidades) quanto como formatos (para serem reproduzidos e/ou reinventados segundo os códigos culturais dos outros países). Tal expansão e êxito chamou atenção de mercados de grande credibilidade no cenário global, como o estadunidense, por exemplo, que comprou os direitos do K-drama Good Doctor 굿 닥터 (KBS2, 2013) e lançou sua versão de série homônima em setembro de 2017, e da plataforma de streaming Netflix, que apenas em seu catálogo brasileiro possui mais de uma centena de dramas e programas televisivos sul-coreanos (MAZUR, 2018; URBANO, 2020), além de estar investindo massivamente na produção de K-dramas para o seu catálogo global (MEIMARIDIS; MAZUR; RIOS, 2020).

Existe, então, um crescente interesse pelo conteúdo produzido pela indústria televisiva sul-coreana, que se expande pelo mundo e se apresenta como uma alternativa em meio ao fluxo globalizante existente (ESPIRITU, 2011; ALBUQUERQUE; CORTEZ, 2015; YANG, 2007). Portanto, este artigo se propõe a apresentar, através de uma abordagem introdutória, questões relacionadas à formação da indústria televisiva sul-coreana, seus conteúdos e influências, focando especialmente no seu carro-chefe: os dramas de TV. Uma vez que o fenômeno da Hallyu e a televisão sul-coreana ainda são temas recentes nos debates acadêmicos brasileiros, é proposto aqui um extenso levantamento 
bibliográfico sobre esse cenário, com a proposta de ser recurso didático ao apresentar um mapeamento da televisão na Coreia do Sul. Parte-se aqui do pressuposto que a melhor compreensão desses processos e indústrias culturais contribuirá para a forma como entendemos a ascensão dessas produções ao redor do mundo, em específico, e os fluxos e contrafluxos globais televisivos, em geral.

\section{Breve introdução à televisão sul-coreana}

A televisão foi introduzida na Coreia do Sul em 1956 e regulada apenas durante os anos 1960, quando a nação estava em processo de reestruturação pós-guerra com os planos quinquenais de desenvolvimento econômico idealizados pelo recém-implementado governo ditatorial. No início, as grades de programação das poucas emissoras existentes eram basicamente preenchidas por produtos importados, especialmente dos Estados Unidos, já que o país asiático ainda não possuía a estrutura necessária para produzir seus próprios conteúdos televisivos em alta escala e o país ocidental era um parceiro político-econômico de influência cultural direta (LEE, 2004; JIN, 2007).

A indústria televisiva viveu seu desenvolvimento e expansão em meio ao cenário acelerado de mudanças na infraestrutura e economia do país e também presenciou grandes transformações na sociedade. Uma delas foi a transição democrática no país ao início dos anos 1990 que alavancou mudanças positivas em diversos setores da sociedade, assim como na indústria cultural. A produção televisiva nacional era, até então, controlada e censurada pelo Estado ditatorial e obrigada a produzir conteúdo propagandista. Contudo, a maior liberdade de expressão oferecida pelo fim da ditadura, a entrada de capital privado nas emissoras e a introdução da nova tecnologia de televisão a cabo no país proporcionaram um ambiente mais plural, fértil e competitivo para a produção televisiva nacional (NAM, 2008; SHIM, S., 2008). Nesse momento de efervescência se consagrou o cenário da TV aberta sul-coreana, composto pelas grandes emissoras abertas KBS (Korean Broadcasting System), MBC (Munhwa Broadcasting Corporation) e SBS (Seoul Broadcasting System), que se mantém até hoje em total destaque de audiência e são conhecidas como as Big Three. 
O fomento ao desenvolvimento da indústria cultural na Coreia do Sul se deu especialmente através do governo e da iniciativa privada, que se expandiu com os anos e incentivou a produção de programação televisiva local nas suas primeiras décadas. Junto a esse estímulo, a partir da década de 1970 aconteceu o aumento nas vendas de apareIhos televisores no país, o que criou uma demanda direta de produção de conteúdo a ser exibido nas grandes televisivas das emissoras existentes à época (LEE, 2004). A aposta em produzir narrativas ficcionais foi essencial para preencher a demanda, especialmente através da importação, tradução e aplicação do formato televisivo japonês conhecido como "Drama de TV" (SHIM, D., 2008). Assim, a partir da década de 1980, a produção local se expandiu a tal ponto que começou a superar a dependência de importação de conteúdos televisivos estrangeiros, que lentamente foram marginalizados para os horários menos nobres das emissoras em favor da programação local, especialmente os dramas de TV (KIM, 2019). Com a chegada dos democratizantes anos 1990 na Coreia do Sul, que também foram marcados pela intensos efeitos da Crise Financeira Asiática de 1997, o país encontrou na produção midiática e cultural uma forma de reanimar, atualizar e expandir a economia nacional (LEE, 2002; NAM, 2008).

Os Dramas de TV são um formato televisivo que abrange ficções seriadas produzidas no Leste e Sudeste Asiáticos, e é atualmente o mais difundido nessas regiões (DISSANAYAKE, 2012; CHUA; IWABUCHI, 2008). Os dramas abrangem diferentes gêneros, desde romance e comédia até ação e horror (KIM, 2014). Em linhas gerais, essas produções possuem forte matriz melodramática, que é a principal formadora da estrutura narrativa dessas produções. O formato foi concebido dentro da lógica televisiva japonesa, de onde a Coreia do Sul se apropriou para produzir suas próprias narrativas, assim como foi feito em países como Tailândia e China. O dado nacional é essencial dentro da lógica dos fluxos transnacionais dos dramas de TV, porque a apropriação desse formato induz a aplicação de características e fundamentos da cultura local, já que a forma de se pensar as narrativas e o que funciona ou não para uma audiência é estruturado especialmente pelas demandas culturais de um país. A lógica do mercado de dramas de TV, então, apresenta fluxos que cruzam fronteiras culturais e linguísticas no Extremo Oriente (CHUA, 2008) e continua funcionando de forma eficaz. 
No mercado televisivo internacional, o drama de TV carrega consigo o dado do país de origem, por isso os dramas de TV sul-coreanos são conhecidos como K-dramas ${ }^{3}$, onde o "K" denota "Korea" (Coreia do Sul). Os K-dramas possuem o seu próprio conjunto de práticas culturais e industriais que o caracterizam e o posicionam como um produto de interesse dentro do circuito regional. Foi, então, munidos de suas especificidades, seu dado nacional e sua condição como produto de uma indústria cultural ainda em incipiência, que os K-dramas deram seus primeiros passos em direção ao mercado asiático no final dos anos 1990, com o apoio dos incentivos governamentais e privados. Tal movimento logo resultou na criação de um mercado de exportação intenso, o que gerou frutos culturais, diplomáticos e econômicos preciosos para a Coreia do Sul, além da ascensão da própria Hallyu.

A indústria dos K-dramas, que era desde a década de 1970 uma das maiores fontes locais de entretenimento, foi potencializada através do aumento da produção de suas narrativas e do interesse em aperfeiçoar esse formato em favor da televisão nacional. A aposta em conteúdo mais jovem e cosmopolita nos anos 1980, inspirado na tendência dos Trendy dramas ${ }^{4}$ japoneses, rapidamente intensificou o interesse do público pelos dramas de TV locais e as emissoras logo estavam com suas grades de programação repletas de produtos desse formato. Os K-dramas conseguiram equilibrar uma abordagem híbrida entre fatores nacionais e estrangeiros, uma vez que a Coreia do Sul participava desse lugar de influências mistas em razão de questões de caráter político, econômico e diplomático. Então, com um produto que harmonizava questões inerentemente tradicionais e regionais (que conseguiam refletir um certo sentimento coletivo cultural do Leste Asiático) com as ocidentais (que representavam influências capitalistas de uma "modernidade" globalizada), e agraciados pelo timing certo, os K-dramas adentraram o mercado transnacional leste asiático.

\footnotetext{
3 Daqui em diante usaremos este termo para designar os dramas de TV sul-coreanos.

4 Segundo Ota (2004), a fórmula dos Trendy dramas consiste-se de elementos como cenário, elenco e música, somados a uma história trágica de amor não correspondido, abordando de forma mais realística a vida moderna e acelerada dos japoneses. Temas como relacionamentos amorosos e vida sexual, em uma narrativa mais rápida, refletindo a vida urbana, eram características dessas produções. A estética refinada das produções e as escolhas de elencos focadas em jovens e belos atores também fazem parte deste universo e se refletem até hoje nos dramas de TV. São estes aspectos singulares estruturados pelos Trendy dramas que hoje continuam definindo a grande maioria dos dramas de TV desenvolvidos pelas indústrias televisivas dos países do Leste e Sudeste da Ásia.
} 


\section{A TV sul-coreana no contexto do Leste da Ásia}

O mercado transnacional leste asiático, especialmente entre os anos 1980 e 1990, era dominado pelos produtos televisivos japoneses e honcongueses (IWABUCHI, 2004). Até o final dos anos 1980, a lógica de um mercado de produtos e formatos televisivos dentro da região do leste asiático ainda era muito incipiente, já que os países temiam que a importação de conteúdos estrangeiros deturpasse as culturas locais. Existia, então, certo caráter protecionista regendo a região (SHIM, D., 2008). No entanto, com a chegada dos anos 1990, as mudanças nas políticas midiáticas regionais através do levante da liberação midiática acabaram se alastrando pela Ásia Oriental, dando espaço para movimentações mais intensas no mercado televisivo regional.

Foi a partir desse cenário de abertura, que a Coreia do Sul conquistou seus primeiros públicos estrangeiros para exportação e consumo de dramas de TV. Começando sua expansão pelos territórios da esfera chinesa, como China, Hong Kong e Taiwan, passando pelo Vietnã, para então conquistar o Japão e outros países. Com esses primeiros passos televisivos para além-Coreia, outros produtos nacionais começaram a ser difundidos para esses mercados estrangeiros, dando-se assim início ao fenômeno cultural da Onda Coreana.

Outro fator crucial para entender a entrada dos produtos culturais da Coreia do Sul no mercado regional foi a Crise Financeira Asiática de 1997 e isso seu deu por dois motivos. O primeiro foi a limitação interna de importar conteúdo televisivo uma vez que o país estava quebrado financeiramente, então a produção local de programas foi incentivada para evitar gastos desse tipo, o que alimentou, assim, o cenário nacional de produção televisiva. Jin (2007) aponta que, entre 1996 e 2001, a importação sul-coreana de programas televisivos estrangeiros caiu $70.5 \%$ pelo valor do dólar, especialmente os canais a cabo tiveram cortes de orçamento e quedas drásticas na compra desses produtos, refletindo o déficit da crise. Enquanto isso, a quantidade de produtos audiovisuais produzidos internamente cresceu de forma rápida com o desenvolvimento e incentivo da indústria cultural sul-coreana no período pós-crise de 1997. Assim, a indústria midiática nacional aumentou sua produção televisiva e suas exportações de produtos culturais. 
O segundo motivo se deu pela instabilidade financeira da época que acabou se tornando o ambiente ideal para a Coreia do Sul entrar no mercado de exportação cultural da região. Ao reduzir o preço de seus programas televisivos, colocando-os abaixo da média de mercado, atraiu importadores. Custando um quarto do preço dos dramas japoneses e um décimo do preço dos honcongueses (CHUA; IWABUCHI, 2008; SHIM, D., 2008), os K-dramas conseguiram atender as demandas de países que estavam passando por sérios problemas financeiros, mas que precisavam de conteúdo televisivo para preencher suas grades de programação. Dessa forma, a Coreia do Sul começou a se estabelecer no mercado regional e de forma gradual se tornou um polo de exportação de dramas de TV e, posteriormente, de cultura pop em geral. Então, a Crise de 1997 somada a liberação midiática que se alastrava pelo continente, além da gradual queda na popularidade dos dramas japoneses na região ${ }^{5}$ e o aumento na produção de entretenimento sul-coreano, foram o cenário ideal para a entrada e o enraizamento da Coreia do Sul no mercado regional.

O sucesso da cultura pop da Coreia do Sul no mercado leste asiático começou a ficar mais em evidência no final dos anos 1990, quando a imprensa chinesa apontou a popularidade crescente desses produtos na China chamando-a de "Onda Coreana" (em mandarim e romanizado, Hanlyu, e em coreano e romanizado, Hallyu) (JANG; PAIK, 2007; SHIM, 2006). Em 1997, o K-drama What Is Love All About 사랑이 뭐길래 (MBC, 1991-1992) tinha se tornado um hit na televisão chinesa ${ }^{6}$, o que abriu espaço para que outros produtos culturais sul-coreanos entrassem no mercado e conquistassem o público local. Logo esse sucesso na China reverberou para os países vizinhos, como o Vietnã, por exemplo, que em 1998 a sua importação de programação televisiva já era dominada pela Coreia do Sul em 58\% (SHIM, D., 2008). A China foi a primeira grande importadora da Hallyu e parte essencial para o desenvolvimento da cultura sul-coreana como um fenômeno transnacional (JOO, 2011; SHIM, 2006). Esse consumo se deu especialmente porque os K-dramas, mesmo sendo estrangeiros, dialogavam com matrizes da cultura chinesa, se tornando uma alternativa mais segura do que os produtos ocidentais.

5 Os dramas japoneses começaram a ser percebidos pelo público leste asiático como muito "ocidentais", porque estavam abordando questões menos atraentes para as culturas envolvidas nesse mercado, então a popularidade desses produtos caiu, situação que foi agravada pelo seu alto preço de mercado na época.

6 Tamanho foi o sucesso entre os telespectadores chineses, que foi reexibido em 1998, dessa vez no horário nobre da grade e bateu o recorde de segunda maior audiência de um produto importado na TV chinesa à época (SHIM, 2006). 
Esse diálogo cultural que a Coreia do Sul travou com a China se repetiu com outros países da região, por essa razão que a Proximidade Cultural é um fator que ajuda a explicar a circulação dos produtos televisivos sul-coreanos pelo Leste e Sudeste Asiático. Segundo Straubhaar (1991), as audiências dão preferência a produtos que dialogam com a sua cultura, buscando familiaridade e representação do seu cotidiano. Essa região compartilha de fluxos culturais compartilhados e construídos por séculos de trocas e interlocuções, o que criou uma certa coletividade cultural imaginada entre os públicos locais, facilitando alguns dos diálogos através de produtos culturais. É o que Fung (2007) chama de "valores celebrados regionalmente" e Chua (2004) aponta como um imaginário generalista de uma "identidade leste-asiática", resultados de séculos de interações históricas de caráter especialmente político-diplomático, fluxos migratórios (naturais ou forçados), escambos culturais, memórias coletivas compartilhadas e da própria cercania geográfica (MAZUR, 2021).

O apelo dos K-dramas provou seu potencial de consumo e valor de soft power quando conseguiu adentrar um dos mercados locais mais concorridos e autossuficientes da época na região: o japonês. Partindo do fato que Japão e Coreia do Sul têm um histórico marcado por invasões e um processo cruel de colonização imposto pelos japoneses aos coreanos, o mercado de produtos culturais entre esses dois países é delicado e difícil. A Onda Coreana conseguiu aliviar algumas das tensões mercadológicas existentes nesse setor. Além disso, o mercado televisivo japonês era referência na época e conseguia cobrir basicamente toda a sua demanda interna, então pouco era importado de países vizinhos (CHUA; IWABUCHI, 2008). Contudo, em 2003, o K-drama Winter Sonata 겨울연가 (KBS2, 2002) foi exibido em um canal a cabo japonês em versão dublada e conseguiu conquistar um sucesso gigantesco, como nunca imaginado para um produto televisivo sul-coreano nesse mercado. Tamanha foi a audiência nessa primeira exibição, que no mesmo ano foi reprisado e pouco depois exibido em emissora aberta para todo o Japão (HANAKI et al, 2007). Posteriormente, foi retransmitido tanto na TV aberta quanto na fechada, além de ser veiculado em versão com áudio coreano e legendas em japonês.

A história de amor cheias de altos e baixos entre Jung Yujin (Choi Jiwon) e Kang Junsang (Bae Yongjoon) conquistou especialmente as japonesas de meia-idade, que logo transformaram o ator protagonista 
em um ídolo nacional e começaram a consumir outros produtos relacionados ao drama e a cultura sul-coreana. Um fluxo inesperado de visitas de japoneses a Coreia do Sul para visitar as locações de Winter Sonata marcou um momento histórico-diplomático que intensificou as relações de consumo entre os dois países (HANAKI et al, 2007). O impacto desse K-drama no Japão é reconhecido como o primeiro efeito de grande porte do soft power sul-coreano através da Hallyu, que conseguiu favorecer até mesmo relações diplomáticas.

Por mais que Winter Sonata tenha conquistado o Japão e outros países, a ampliação das exportações de K-dramas para o mundo tem um outro expoente de sucesso: Jewel in the Palace 대장금 (MBC, 2003-2004). Esse drama foi o primeiro a ser amplamente aclamado fora do país e é um marco do início da fundamentação da Hallyu como um fenômeno transnacional. Jewel in the Palace foi vendido para mais de 80 países, dentro e fora da Ásia, uma revolução para a indústria de entretenimento sul-coreana à época (KIM; WANG, 2012). Baseado em fatos reais, Jewel in the Palace é um drama do gênero histórico, que se passa durante a Dinastia Joseon (1392-1910) e aborda a história da primeira mulher que se tornou médica da realeza. Por ser um drama sobre o passado e repleto de referências culturais e tradições específicas, o seu sucesso de exportação foi uma surpresa, não era esperado que ele fosse ter apelo para outros públicos além do interno. Dessa forma, Jewel in the Palace fortaleceu o turismo da Coreia do Sul, fãs estrangeiros visitavam as locações e o parque em homenagem ao drama, Daejanggeum Theme Park (KIM; WANG, 2012).

De acordo com o Ministério de Cultura e Turismo da Coreia do Sul (2005), o lucro com a exportação de programas televisivos sul-coreanos cresceu de 5.5 milhões de dólares em 1995 para 71.5 milhões de dólares em 2004, dentre essas exportações os K-dramas representavam a maior fatia em 2002 (76,8\%), seguida pelas animações e programas de variedades. Pela primeira vez, em 2002, a Coreia do Sul conseguiu que as exportações de conteúdo televisivo superassem as importações de produtos de mesmo caráter, se mantendo independente de importação de programação estrangeira (JIN, 2007; SHIM, D. 2008).

Em meio ao fluxo crescente de produtos televisivos no mercado leste asiático, os formatos começaram a ser difundidos e versões licenciadas de dramas sul-coreanos surgiram em diferentes países, assim como versões de dramas de outros países ganharam suas versões 
sul-coreanas. Por exemplo, o K-drama Boys Over Flowers 꽃보다 남자 (KBS, 2009) é uma adaptação do mangá7 e do drama de TV japonês Hana Yori Dango 花より男子 (TBS, 2005), e Full House วุนนัก รักเต็มบาน (TrueVision, 2014) é a versão tailandesa do drama sul-coreano Full House풀하우스 (KBS, 2004). Dentro deste universo, os dramas de TV conseguem circular narrativas que abrangem não só a venda de produtos licenciados, mas também formatos de roteiro, criando um ambiente fértil para as adaptações e traduções culturais entre essas indústrias (MAZUR, 2021). A Hallyu e os K-dramas conquistaram espaço nesse contexto e fazem parte dos fluxos mercadológicos e culturais existentes nessa rica conjuntura asiática, impulsionando em direção aos mercados além-Ásia.

\section{A TV sul-coreana no atual contexto global}

A Onda Coreana, então, teve seu início como um fenômeno de caráter de expansão regional através do sucesso dos dramas de TV. Foi a partir disso que a indústria cultural sul-coreana começou a desenvolver estratégias de exportação e alcance, conseguindo gradualmente entrar do mercado global e expandir seu potencial de venda em outros setores. Graças ao aumento do interesse por parte do público estrangeiro, o papel da Hallyu como um instrumento econômico e de identidade nacional expandiu (JIN, YOON, 2017). Passou, então, a capturar a atenção e maiores incentivos do governo, que objetivou a capitalização desse fenômeno em favor do soft power (NYE, 2004) nacional para, assim, se transformar em um polo de influências no cenário internacional. E, como discutido anteriormente, os dramas de TV sul-coreanos se tornaram um destaque dentro dos fluxos televisivos existentes no Leste e Sudeste Asiáticos, diversos autores acadêmicos apontam a recepção dos K-dramas em territórios dessas regiões, como Japão (HANAKI et al, 2007; LEE; JU, 2010), Singapura (CHAN; WANG, 2011; SHIM, 2007), Filipinas (ESPIRITU, 2011; CLEMENTE, 2020) e Taiwan (HUANG, 2011; YANG, 2012). Outros pesquisadores apontam uma questão ainda mais contemporânea, que é a chegada dessas narrativas em outras regiões

7 História em quadrinhos japonesa. 
do mundo, como América Latina (IADEVITO; BAVOLEO; LEE, 2010; HAN, 2019), Gana (KIM, 2017), Índia (KANOZIA; GANGHARIYA, 2021), Canadá (YOON, 2020) e Espanha (MADRID-MORALES; LOVRIC, 2015).

No cenário brasileiro, o catálogo nacional da plataforma de streaming de filmes e séries Netflix se apresenta como um termômetro interessante. O catálogo da Netflix Brasil possui atualmente mais de uma centena de produtos audiovisuais da Coreia do Sul disponíveis, entre eles estão K-dramas, filmes, reality shows ${ }^{8}$ e programas de variedades (MAZUR, 2018; URBANO, 2020). Desde 2016, quando a Netflix chegou à Coreia do Sul, que a programação sul-coreana cresce no catálogo global da plataforma, assim como o interesse dos consumidores internacionais. Em 2019, foi firmada uma parceria de três anos entre a empresa de streaming e a produtora sul-coreana Studio Dragon, para o desenvolvimento de títulos inéditos e o licenciamento de K-dramas já consagrados (MEIMARIDIS; MAZUR; RIOS, 2020). A plataforma, que até pouco tempo atrás era praticamente formada apenas por produtos ocidentais, apresenta seu interesse em conteúdo sul-coreano e asiático em geral (JU, 2019), deixando claro que o impacto das produções e movimentações que estão acontecendo nas últimas décadas no mercado leste asiático geram interesse pelo mundo.

Percebe-se que a demanda por esses produtos está crescendo não só no Brasil, mas no Ocidente como um todo. Surgiram plataformas de legendagem e exibição de conteúdo televisivo com foco na Coreia do Sul, como o KOCOWA e o Viki, além de sites de fansub ${ }^{9}$ que partem de esforços dos fãs em circular os dramas e programas sul-coreanos. Desde o final dos anos 2000, que os conteúdos sul-coreanos têm conquistado públicos além-Ásia. Esse consumo é possibilitado especialmente pela ascensão da Web 2.0 como um instrumento de difusão pelo mundo, que serve como espaço para trocas entre fãs e compartilhamento de conteúdo. A indústria cultural sul-coreana encontrou na internet um ambiente fértil para disponibilizar suas produções televisivas e musicais, inicialmente em favor de facilitar e aumentar o consumo em países vizinhos que já eram consumidores de sua cultura. Contudo, através de plataformas como Youtube e Facebook, os clipes musicais e os dramas

8 Formato televisivo que abrange vários gêneros e dá conta de uma alegoria da vida real. No caso dos reality shows sul-coreanos, estes abordam o dia a dia de celebridades e/ou anônimos, tanto em suas vidas privadas, quanto profissionais, ou através de competições, viagens, entre outros.

9 Fãs que legendam conteúdos audiovisuais, especialmente séries e filmes, para serem disponibilizados a outros fãs. 
de TV começaram a serem visualizados por outros países que ainda não consumiam oficialmente a cultura pop sul-coreana. Foi, então, a partir da difusão online e do interesse crescente dos fãs internacionais por esses produtos, que a Hallyu se movimentou nos fluxos globais em direção ao Ocidente. Esse fenômeno cultural é hoje caracterizado especialmente pelo seu alcance, produção e consumo através das redes sociais online (YOON, JIN, 2014).

Desde a sua consolidação no mercado asiático, a indústria sul-coreana aposta em estratégias para globalizar a Hallyu. Uma delas foi direcionada a América Latina, através da concessão de direitos de exibição de K-dramas para emissoras de alguns desses países, sem nenhum custo (IADEVITO; BAVOLEO; LEE, 2010) no final dos anos 2000. A ideia seguiu a mesma lógica utilizada para a entrada no mercado leste asiático: começar cobrando pouco ou nada por seus produtos para engajar um público consumidor estável. A América Latina se apresentou a Coreia do Sul como um mercado distante e muito diferente culturalmente, mas com demandas e interesses por narrativas de caráter melodramático, especialmente em razão de sua circulação regional de telenovelas. O interesse desse mercado regional em conteúdo de raízes melodramáticas dialogou diretamente com o conceito inerente ao formato dos dramas de TV, o que reitera que a matriz melodramática é de potencial inerentemente transnacional, superando os traços culturalmente específicos dos K-dramas e fortalecendo seu apelo transcultural (HAN, 2019).

Os K-dramas, através de suas trilhas sonoras e elencos repletos de ídolos da música, conseguiram difundir o universo musical sul-coreano para o mundo. Tanto que, hoje, o K-pop tem força global ainda mais poderosa do que os próprios K-dramas, mas deve o início da sua difusão internacional a eles. Outros produtos televisivos sul-coreanos que se destacam no mercado de exportação atualmente são os reality shows e os programas de variedades. A presença de celebridades da Hallyu e o fato desses programas apresentarem um pouco mais sobre o cotidiano da vida na Coreia do Sul desperta o interesse dos fãs internacionais. A Hallyu hoje não só comercializa produtos culturais, mas também um estilo de vida, e esses programas são mais uma forma de circular essa estratégia. A partir do sucesso dessa programação, a indústria televisiva sul-coreana, além de lucrar vendendo produtos licenciados, também lucra com formatos. A China, por exemplo, compra esses formatos e lança 
suas próprias versões. Running Man 런닝맨 (SBS, 2010-) é um exemplo: é um dos reality shows de maior sucesso da Coreia do Sul e possui grande reconhecimento no Leste Asiático, tanto que ganhou em 2014 sua versão chinesa intitulada de Keep Running 奔跑吧 (Zhejiang Television).

Assim como o Leste Asiático se apropria de formatos televisivos sul-coreanos para produzir suas versões, o Ocidente começou a fazer o mesmo. Os Estados Unidos, o mercado mais disputado do mundo, comprou os direitos do K-drama Good Doctor 굿닥터 e lançou a série homônima pela emissora ABC em 2017, assim como tem sua versão do reality King of Mask Singer 미스터리 음악쇼 복면가왕 (MBC, 2015-) que foi adaptado para o público estadunidense como The Masked Singer (Fox, 2019-). Antes disso, o país norte-americano produziu sua versão do reality show sul-coreano Grandpa Over Flowers 꽃보다 할배 (TVN, 2013-2015), que foi intitulada de Better Late Than Never pela NBC em 2016. Tal demanda ocidental por esses produtos levou as emissoras sul-coreanas, como MBC e SBS, a lançarem seus próprios canais no Youtube com grande parte do seu conteúdo legendado para vários idiomas e também disponibilizarem seu sinal de satélite para outros países. Parte desse esforço vem especialmente da tradução, legendagem e dublagem desses produtos (já que o idioma coreano, o hangul, é usado oficialmente apenas na Coreia do Sul e na Coreia do Norte).

Em suma, o contexto além-Ásia da televisão sul-coreana e da Hallyu ainda está em construção e é intrínseco ao consumo online. O contrafluxo gerado pela entrada da televisão sul-coreana no Ocidente e em outros países de fora do alcance do Leste e Sudeste da Ásia ainda demanda que seja estendido para plataformas oficiais, como emissoras de televisão e cinema, para conseguir alcançar consumidores além do nicho dos fãs da Hallyu. Plataformas de streaming, globais ou locais, são uma opção relevante para continuar impulsionando a produção televisiva sul-coreana para fora de suas fronteiras. A Coreia do Sul, atualmente, exporta um estilo de vida e uma identidade atualizada do que é ser sul-coreano através de suas diversas vertentes culturais, o que está impulsionando essa indústria a alcançar mercados ainda mais distantes. A presença dos dramas de TV em canais latinos e na Netflix, por exemplo, está ampliando o potencial transnacional da televisão sul-coreana, que, mesmo com suas limitações idiomáticas e culturais, está lentamente conquistando espaço no cotidiano ocidental e se enraizando como parte dos fluxos televisivos globais. 


\section{Considerações Finais}

Em meio a atual ecologia global e aos fluxos televisivos que abarcam o mercado mundial, formas atualizadas de se assistir e produzir televisão estão surgindo e conquistando espaço no cenário internacional. A televisão sul-coreana, que até pouco tempo atrás era uma desconhecida nos fluxos globais, hoje se apresenta como um polo estável de exportação e influência audiovisual. O fenômeno de ascensão cultural pop da Coreia do Sul apresenta a efervescência dos mercados nacionais e regionais e mostra como a televisão é um instrumento poderoso de construção e difusão de identidades, além de apontar como as movimentações dos fluxos televisivos estão alcançando novas abordagens do que é ser global no mundo de hoje. O universo midiático apresenta formas de se ler o mundo, que atualmente não refletem apenas questões ocidentais, mas uma pluralidade cultural realmente globalizada. Por essa razão é que a representação das especificidades nacionais nas narrativas audiovisuais é tão importante. A televisão se posiciona como um espaço essencial para a difusão dessa pluralidade, já que é uma ferramenta midiática muito difundida, que participa diretamente do cotidiano dos seus receptores.

Partindo do fato que abordamos o caso da TV sul-coreana através do olhar brasileiro, Brasil e Coreia do Sul criam um debate cultural essencial e urgente à Academia brasileira. Ambas são nações da periferia global que se tornaram referenciais internacionais em contrafluxo televisivo. As novelas brasileiras são um precedente para os K-dramas, elas se aventuraram no mercado global antes, criaram e ainda criam imaginários atualizados sobre o Brasil sem a mediação "globalizada" e central dos Estados Unidos e Reino Unido. É o Brasil definindo, por vias da ficção, como é representado no mercado de exportação e no consumo cultural internacional. O mesmo faz hoje a Coreia do Sul, de forma ainda mais potente, apoiada por todo um fenômeno cultural que se alastra pelo mundo. Por isso, Brasil e Coreia do Sul se aproximam, mesmo tão distantes, fazem parte de um mesmo movimento de resistência em produção e circulação de suas narrativas para o resto do mundo e, hoje, a indústria cultural brasileira pode aprender muito com essa nação asiática. Além disso, dentro da lógica de dominação do centro global, a ascensão em termos culturais através do audiovisual 
televisivo cria diálogos importantes especialmente com outros países que também não fazem parte das lógicas centrais de poder, criando espaços de resistência que são essenciais.

Por fim, nesse artigo procuramos, através de extenso levantamento bibliográfico, fazer um estudo introdutório sobre a formação da televisão sul-coreana como parte de um fluxo global multipolarizado. Partindo das características e da contextualização do desenvolvimento da indústria cultural na Coreia do Sul, passamos por especificidades dessa ascensão regional dentro do Leste e Sudeste Asiáticos e também da atual jornada do país a fim de se afirmar nos fluxos globais. Nosso objetivo, mesmo que incipiente, foi o de compreender como o conteúdo televisivo de uma indústria cultural tão recente em sua empreitada televisiva conseguiu conquistar diferentes esferas regionais do mundo. Os dramas de TV se mostram como fortes instrumentos dessa difusão cultural e são essenciais para compreender como a televisão sul-coreana chegou aonde está e quais serão os próximos passos para que conquiste outros públicos. O caráter dessas narrativas ficcionais revela estratégias mercadológicas que apresentam também a estrutura da indústria cultural do país. Portanto, percebemos que esse processo de ascensão de novos polos de produção midiática não só apresenta outras formas de se pensar o mundo, mas também de como criar significados atualizados que façam real sentido dentro do contexto cada dia mais global da mídia.

\section{REFERÊNCIAS}

ALBUQUERQUE, Afonso; CORTEZ, Krystal. Cultura pop e política na nova ordem global: lições do Extremo-Oriente. In: SÁ, Simone; CARREIRO, Rodrigo; FERRAZ, Rogerio (org.). Cultura Pop. Salvador: EDUFBA, 2015.

BERG, Miriam. The importance of cultural proximity in the success of Turkish dramas in Qatar. International Journal of Communication, v. 11, p. 16, 2017.

CHAN, Brenda; WANG, Xueli. Of prince charming and male chauvinist pigs: Singaporean female viewers and the dream-world of Korean television dramas. International Journal of Cultural Studies, v. 14, n. 3, p. 291-305, 2011.

CHUA, Beng Huat. Conceptualizing an East Asian popular culture. Inter-Asia Cultural Studies, v. 5, n. 2, p. 200-221, 2004. 
$\mathrm{CHUA}$, Beng Huat. Structure of identification and distancing in watching East Asian television drama. East Asian pop culture: Analysing the Korean wave, v. 1, p. 73, 2008.

CHUA, Beng Huat; IWABUCHI, Koichi. East Asian TV dramas: identifications, sentiments, and effects. In: East Asian pop culture: Analysing the Korean wave. Hong Kong University Press, p. 1-12, 2008.

CLEMENTE, Tina S. A Look at Korean Historical Drama: Cultural Negotiation of Cold War Influence on Notions of Development in the Philippines. Asian Perspective, v. 44, n. 2, p. 303-326, 2020.

DISSANAYAKE, Wimal. Asian television dramas and Asian theories of communication. Journal of Multicultural Discourses, v. 7, n. 2, p. 191-196, 2012.

ESPIRITU, Belinda Flores. Transnational audience reception as a theater of struggle: young Filipino women's reception of Korean television dramas. Asian Journal of Communication, v. 21, n. 4, p. 355-372, 2011.

FUNG, Anthony. Intra-Asian cultural flow: Cultural homologies in Hong Kong and Japanese television soap operas. Journal of Broadcasting \& Electronic Media, v. 51, n. 2, p. 265-286, 2007.

HALL, Stuart. The West and the Rest: discourse and power. In: HALL, Stuart.; GIEBEN, Bram. Formations of Modernity. Cambridge: The Open University Press, 1992.

HAN, Benjamin M. Fantasies of Modernity: Korean TV Dramas in Latin America. Journal of Popular Film and Television, v. 47, n. 1, p. 39-47, 2019

HANAKI, Toru et al. Hanryu sweeps East Asia: How winter sonata is gripping Japan. International Communication Gazette, v. 69, n. 3, p. 281-294, 2007.

HUANG, Shuling. Nation-branding and transnational consumption: Japan-mania and the Korean wave in Taiwan. Media, Culture \& Society, v. 33, n. 1, p. 3-18, 2011.

IADEVITO, Paula; BAVOLEO, Bárbara; CHINKYONG LEE, Mónica. Telenovelas coreanas en América Latina:¿ una nueva forma decomunicación intercultural?. In: VI Jornadas de Sociología de la UNLP 9 y 10 de diciembre de 2010 La Plata, Argentina. Universidad Nacional de La Plata, 2010.

IWABUCHI, Koichi. Feeling glocal: Japan in the global television format business. In: Television Across Asia. Routledge, p. 33-47, 2004.

JANG, Gunjoo; PAIK, Won K. Korean Wave as tool for Korea's new cultural diplomacy. Advances in Applied Sociology, v. 2, n. 03, p. 196, 2012.

JIN, Dal Yong. Reinterpretation of cultural imperialism: Emerging domestic market vs continuing US dominance. Media, Culture \& Society, v. 29, n. 5, p. 753-771, 2007.

JIN, Dal Yong; YOON, Kyong. The social mediascape of transnational Korean pop culture: Hallyu 2.0 as spreadable media practice. New Media \& Society, v. 18, n. 7, p. 1277-1292, 2014.

JIN, Dal Yong; YOON, Tae-Jin. The Korean Wave: retrospect and prospect introduction. International Journal of Communication, v. 11, p. 2241-2249, 2017.

JOO, Jeongsuk. Transnationalization of Korean popular culture and the rise of "pop nationalism" in Korea. The journal of popular culture, v. 44, n. 3, p. 489-504, 2011.

JU, Hyejung. Korean TV drama viewership on Netflix: Transcultural affection, romance, and identities. Journal of International and Intercultural Communication, 2019. 
KANOZIA, Rubal; GANGHARIYA, Garima. Cultural proximity and hybridity: popularity of Korean pop culture in India. Media Asia, p. 1-14, 2021.

KIM, Jeongmee. East Asian television drama: A story of booms, fevers, and waves. Reading Asian Television Drama: Crossing Borders and Breaking Boundaries. London: Ib Tauris, p. 1-24, 2014.

KIM, Sangkyun; WANG, Hua. From television to the film set: Korean drama Daejanggeum drives Chinese, Taiwanese, Japanese and Thai audiences to screen-tourism. International Communication Gazette, v. 74, n. 5, p. 423-442, 2012.

KIM, Suweon. Who watches Korean TV dramas in Africa? A preliminary study in Ghana. Media, Culture \& Society, v. 40, n. 2, p. 296-306, 2017.

KIM, Yaeri. The invention of the Mideu: redefining American television in South Korea. Media, Culture \& Society, v. 42, n. 1, p. 109-125, 2019.

LEE, Donghoo. A local mode of programme adaptation: South Korea in the global television format business. In: Television Across Asia. Routledge, p. 48-65, 2004.

LEE, Jae-kyoung. The Asian financial crisis and the tribulations of the South Korean media. Gazette (Leiden, Netherlands), v. 64, n. 3, p. 281-297, 2002.

LEE, Soobum; JU, Hyejung. Korean Television Dramas in Japan: Imagining "East Asianness" and Consuming "Nostalgia". Asian Women, v. 26, n. 2, p. 77-105, 2010.

MADRID-MORALES, Dani; LOVRIC, Bruno. 'Transatlantic connection': K-pop and K-drama fandom in Spain and Latin America. The Journal of Fandom Studies, v. 3, n. 1, p. 23-41, 2015.

MAZUR, Daniela. Um mergulho na Onda Coreana, Nostalgia e Cultura pop na série de K-drama "Reply". (Dissertação de mestrado) PPG em Comunicação. Universidade Federal Fluminense, 2018.

MAZUR, Daniela. Hana Yori Dango e o mercado televisivo transnacional do Leste da Ásia. In: SOUZA, Maria Carmem; ALVES, Lynn. Narrativas Seriadas: Ficções televisivas, games e transmídia. Salvador: Editora UFBA, 2021.

MEIMARIDIS, Melina; MAZUR, Daniela; RIOS, Daniel. A Empreitada Global da Netflix: uma análise das estratégias da empresa em mercados periféricos. Revista GEMInIS, v. 11, n. 1, p. 4-30, 2020.

NAM, Siho. The politics of compressed development in new media: a history of Korean cable television, 1992-2005. Media, Culture \& Society, v. 30, n. 5, p. 641-661, 2008.

NYE, Joseph. Soft Power: the means to success in world politics. New York: Public Affairs, 2004.

OTA, Toru. Producing (Post-)Trendy Japanese TV Dramas. In: IWABUCHI, Koichi. Feeling Asian Modernities: Transnational Consumption of Japanese TV Dramas. Hong Kong: Hong Kong University Press, 2004.

RYOO, Woongjae. Globalization, or the logic of cultural hybridization: The case of the Korean wave. Asian Journal of Communication, v. 19, n. 2, p. 137-151, 2009.

SHIM, Doobo. Hybridity and the rise of Korean popular culture in Asia. Media, culture \& society, v. 28, n. 1, p. $25-44,2006$.

SHIM, Doobo. Korean wave and Korean women television viewers in Singapore. Asian Journal of Women's Studies, v. 13, n. 2, p. 63-82, 2007. 
SHIM, Doobo. The growth of Korean cultural industries and the Korean wave. East Asian pop culture: Analysing the Korean wave, v. 1, p. 15-32, 2008.

SHIM, Sungeun. Behind the Korean Broadcasting Boom. NHK Broadcasting Studies, v. 6, p. 205-232, 2008.

STRAUBHAAR, Joseph D. Beyond media imperialism: Assymetrical interdependence and cultural proximity. Critical Studies in Media Communication, v. 8, n. 1, p. 39-59, 1991.

URBANO, Krystal. Produções televisivas japonesas e sul-coreanas na Netflix Brasil: apontamentos iniciais. Comunicação, Mídia e Consumo, v. 17, n. 50, p. 561-578 2020.

YANG, Fang-chih Irene. From Korean Wave to Korean living: Meteor garden and the politics of love fantasies in Taiwan. Korea Observer, v. 43, n. 3, p. 419-445, 2012.

YANG, Jonghoe. Globalization, nationalism, and regionalization: The case of Korean popular culture. Journal of Asian Sociology, v. 36, n. 2, p. 177-199, 2007.

YOON, Kyong. Diasporic Korean Audiences of Hallyu in Vancouver, Canada. Korea Journal, v. 60, n. 1, p. 152-178, 2020.

Recebido em: 20/04/20

Aprovado em: 27/01/21 


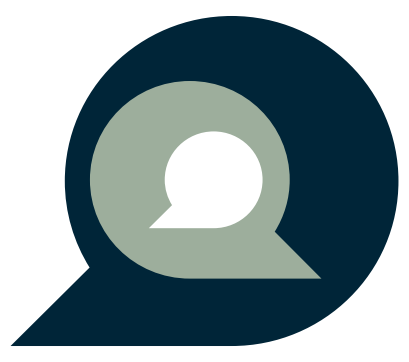

